\title{
Association of functional polymorphisms in CYP19A1 with aromatase inhibitor associated arthralgia in breast cancer survivors
}

Jun J Mao ${ }^{1,2^{*}+}, \mathrm{H}$ Irene Su${ }^{3+}$, Rui Feng ${ }^{4}$, Michelle L Donelson ${ }^{4}$, Richard Aplenc ${ }^{5}$, Timothy R Rebbeck ${ }^{2,4}$, Frank Stanczyk ${ }^{6}$, Angela DeMichele $e^{2,4,6}$

\begin{abstract}
Introduction: Aromatase inhibitor-associated arthralgia (AIAA) is a common and often debilitating symptom in breast cancer survivors. Since joint symptoms have been related to estrogen deprivation through the menopausal transition, we hypothesized that genetic polymorphisms in CYP19A1, the final enzyme in estrogen synthesis, may be associated with the occurrence of AIAA.

Methods: We performed a cross-sectional study of postmenopausal women with stage 0 to III breast cancer receiving adjuvant aromatase inhibitor (Al) therapy. Patient-reported AIAA was the primary outcome. DNA was genotyped for candidate CYP19A1 polymorphisms. Serum estrogen levels were evaluated by radioimmunoassay. Multivariate analyses were performed to examine associations between AIAA and genetic variants controlling for possible confounders.

Results: Among 390 Caucasian participants, 50.8\% reported AIAA. Women carrying at least one 8-repeat allele had lower odds of AIAA (adjusted odds ratio (AOR) 0.41, 95\% confidence interval (CI) 0.21 to $0.79, P=0.008$ ) after adjusting for demographic and clinical covariates. Estradiol and estrone were detectable in $47 \%$ and $86 \%$ of subjects on Als, respectively. Although these post-Al levels were associated with multiple genotypes, they were not associated with AIAA. In multivariate analyses, women with more recent transition into menopause (less than five years) were significantly more likely to report AIAA than those greater than ten years post-menopause (AOR 3.31, $95 \% \mathrm{Cl} 1.72$ to $6.39, P<0.001)$.

Conclusions: Functional polymorphism in CYP19A1 and time since menopause are associated with patientreported AIAA, supporting the hypothesis that the host hormonal environment contributes to the pathophysiology of AAIA. Prospective investigation is needed to further delineate relationships between host genetics, changing estrogen levels and AIAA.
\end{abstract}

\section{Introduction}

Joint pain, or arthralgia, has emerged as a major symptom in breast cancer survivors on aromatase inhibitors (AIs) for adjuvant hormonal therapy [1,2]. In clinical settings outside of therapeutic trials, close to half of patients on AIs attribute arthralgia to this class of medication $[3,4]$. AI-associated arthralgia (AIAA) results not

\footnotetext{
* Correspondence: maoj@uphs.upenn.edu

+ Contributed equally

'Department of Family Medicine and Community Health, University of Pennsylvania School of Medicine, 3400 Spruce Street/2 Gates, Philadelphia, PA 19104, USA

Full list of author information is available at the end of the article
}

only in decreased function [5], but also in premature discontinuation and sub-optimal adherence [6]. Thus, this symptom has the potential to impair both quality of life and drug effectiveness.

Although the pathophysiology of AIAA remains unclear, estrogen suppression is hypothesized to play an important role, since AIs block the final step in estradiol and estrone synthesis [7]. Natural menopause has been associated with increased joint aches and stiffness; symptoms are most prominent during the late menopausal transition when marked falls in circulating estrogen levels occur [8]. Among breast cancer survivors,
Ciomed Central

(c) 2011 Mao et al.; licensee BioMed Central Ltd. This is an open access article distributed under the terms of the Creative Commons Attribution License (http://creativecommons.org/licenses/by/2.0), which permits unrestricted use, distribution, and reproduction in any medium, provided the original work is properly cited. 
clinical risk factors associated with AIAA include shorter time since menopause [3] and chemotherapy exposure [4], which further diminishes residual ovarian estrogen production. Thus, estrogen suppression, the main effect of AI exposure, appears linked to arthralgia.

Aromatase enzyme, encoded by CYP19A1 and inhibited by AIs, contains common genetic variants that have been associated with circulating estrogen levels in postmenopausal women [9-12]. In particular, intron 4 contains a tetranucleotide repeat polymorphism $(\text { TTTA })_{n}=$ 7-13 associated with estrogen levels. Postmenopausal women who carry at least one 7-repeat allele (TTTA7) have been found to have lower circulating estrone and estradiol levels; those who carry at least one 8 -repeat allele (TTTA8) have been noted to have higher estrone and estradiol levels, compared to those with all other repeat lengths.

Since polymorphisms in CYP19A1 impact estrogen levels, we hypothesized that the presence of functional polymorphisms in this gene would be associated with AIAA among postmenopausal breast cancer survivors on AI therapy. To test this hypothesis, we performed a cross-sectional study of postmenopausal women taking AIs to evaluate whether these polymorphisms were associated with patient-reported occurrence of AIAA. Additionally, we tested the feasibility of measuring estradiol and estrone levels in postmenopausal women on AIs and explored their association with candidate genotypes and AAIA.

\section{Materials and methods Study design and patient population}

The Wellness After Breast Cancer (WABC) Study is a cross-sectional study conducted between March 2008 and July 2009 at the Rowan Breast Cancer Center of the Abramson Cancer Center of the University of Pennsylvania (Philadelphia, PA, USA). Eligibility criteria included postmenopausal status ( $\geq 12$ months of amenorrhea), history of histologically-confirmed hormone receptorpositive breast cancer, AJCC stages 0 to III, and exposure to a third-generation aromatase inhibitor (anastrozole, letrozole, or exemestane). Additional eligibility criteria included completion of all chemotherapy and/or radiotherapy at least one month prior to enrollment, approval of the patient's primary oncologist, and ability to provide informed consent. Research assistants screened medical records and approached potential patients for enrollment at their regular follow-up appointments. After informed consent was obtained, each participant completed a selfadministered survey. Peripheral blood was collected; whole blood and serum samples were banked at $-80^{\circ} \mathrm{C}$ for genetic and biomarker analysis, respectively. The study was approved by the Institutional Review Board of the University of Pennsylvania.

\section{Outcome measurement}

We first asked whether participants experienced ongoing joint pain, or arthralgia. Because arthralgia in a postmenopausal female population can be multi-factorial, we then specifically asked participants to attribute their current arthralgia to several factors included aging, AIs, and other medical conditions and medications. As in our prior work, patients who reported AI as a current cause of arthralgia were defined as having AAIA [3]. We also asked those who stopped AIs for discontinuation reasons. Because AIAA is an important cause of premature discontinuation of therapy [13], those who reported stopping AIs because of joint pain or musculoskeletal problems were also classified as having AIAA.

Multiple covariates were ascertained. Patients self-reported demographic variables included age, race/ ethnicity, education status, height, weight, date of last menstrual period (LMP) and reasons for menopause (natural, surgery, chemotherapy, hormonal therapy, and other). Clinical variables such as cancer stage, prior chemotherapy, current aromatase inhibitor use, and time since AI start were obtained via chart abstraction and verified by an oncologist (AD) for quality control.

\section{Polymorphism selection and genotyping}

Detailed literature and National Center for Biotechnology Information single nucleotide polymorphism database searches were performed to identify variants in CYP19A1 that (1) had a functional impact on gene expression, (2) were associated with either estrogen levels, arthralgia or estrogen withdrawal symptoms in the literature, and (3) had minor allele frequencies of $>10 \%$. Five variants in CYP19A1 met these criteria. Variants in CYP19A1 (IVS1 G/A (rs749292), IVS2 C/A (rs727479), 3'UTR T/C (rs10046), IVS4 -/TCT (rs11575899), TTTA $_{n}($ rs60271534)) are associated with estrogen levels $[9,10,14]$ and/or hot flashes, another symptom related to estrogen withdrawal [12].

Genomic DNA was extracted from stored blood samples using the Qiagen QiaAmp 96 DNA Blood Kit (Valencia, CA, USA). Laboratory personnel were blinded to all clinical and outcome data. Genotyping for CYP19A1 TTTA $\mathrm{n}$ was performed using site-specific primers for PCR amplification according to Woods et al. [12] and Kelberman et al. [15] with modifications to PCR conditions followed by direct sequencing. For all other SNPs, genotyping was performed using Applied Biosystems' SNPlex platform (Foster City, CA, USA).

\section{Estrone and estradiol levels}

Serum samples were assayed for estradiol and estrone levels. Samples underwent organic solvent extraction followed by Celite column partition chromatography, followed by radioimmunoassay to quantify estrone and 
estradiol, the primary circulating hormones in postmenopausal women. Assays were performed in duplicate, and means of duplicates were analyzed. The intra- and inter-assay coefficients of variation were $<7 \%$ and $12 \%$, respectively. The lower limits of detection for estradiol and estrone were $1.5 \mathrm{pg} / \mathrm{mL}$ and $1.7 \mathrm{pg} / \mathrm{mL}$, respectively. Values below detection thresholds were given half of the threshold value in analyses.

\section{Statistical analysis}

Data analysis was performed using STATA 10.0 for Windows (STATA Corporation, College Station, TX, USA). Because genetic heterogeneity, or population stratification, could lead to either spurious association or reduced power, we carried out population-specific analysis and report the results restricted to Caucasian subjects since the number of subjects in other ethnic groups was relatively small. For quality control, HardyWeinberg Equilibrium was assessed for each polymorphism using the Pearson chi square test.

First, we examined the association between AIAA and polymorphisms using the $\chi^{2}$ test. Additive, dominant and recessive models were tested separately. The association between AIAA and clinical and demographic variables was tested using the $\chi^{2}$ test or Student's $t$-test, as appropriate. Covariates with $P$-values $<0.2$ in bivariable analyses were carried forward to the multivariable model. Because estrogen levels were not normally distributed (even with logarithmic transformation), the Kruskal-Wallis test was used to compare estrogen levels by genotype and AIAA status.

For those genotypes that were found to be significant in the first step, we further determined the geneoutcome association using multivariate logistic regression models, adjusting for covariates including education, length of time since menopause, reasons for menopause, time since start of AI therapy, and chemotherapy regimen. Bonferroni correction was applied because five polymorphisms were tested, and the level of significance was adjusted to $P<0.01$.

\section{Results}

\section{Participant characteristics}

Of 643 consecutive patients screened, 538 (83.7\%) agreed to participate. Among 105 who declined (16.3\%), the main reasons were: lack of time to complete survey $(n=26,4 \%)$; did not want to participate in research ( $n=43 ; 6.7 \%$ ); and did not want to have an extra blood draw $(n=36 ; 5.6 \%)$. Additionally, one subject withdrew consent and nine subjects (1.4\%) were further disqualified because they did not meet eligibility criteria upon further review. Of 528 subjects who returned data (82.1\%), 501 (77.9\%) had both an evaluable survey and a blood sample. Twenty-five subjects were further excluded after chart review revealed metastatic disease (3.9\%), resulting in the final sample of 476 . This population reflected a $74 \%$ response rate among all initially approached subjects and a $78 \%$ response rate among those eligible.

For this study, we restricted analysis to the 390 Caucasian subjects $(81.9 \%)$ out of the entire sample. Among these subjects (Table 1), mean age was 61.6 (standard deviation (SD) 9.9); 206 subjects (56\%) had gone through natural menopause. Seventy-six subjects (19.0\%) were within five years of menopause, while more than half (53\%) reported being greater than 10 years from menopause. Overall, 355 (91\%) were currently taking an AI at the time of enrollment, while $9 \%$ had discontinued AI therapy by the time of the survey. Among those currently taking an $\mathrm{AI}$, the majority (67.9\%) was taking anastrozole. Of the 35 subjects who had discontinued

Table 1 Demographic characteristics of participants

\begin{tabular}{|c|c|c|}
\hline & $\mathbf{N}$ & $\%$ \\
\hline Total (N, \%) & 390 & 81.9 \\
\hline Age, years (Mean, SD) & 61.6 & 9.88 \\
\hline \multicolumn{3}{|l|}{ Educational Level (N, \%) } \\
\hline High school or less & 69 & 17.7 \\
\hline College or more & 321 & 82.3 \\
\hline \multicolumn{3}{|l|}{ Reasons for menopause (N, \%) } \\
\hline Natural & 206 & 55.7 \\
\hline Induced & 164 & 44.3 \\
\hline \multicolumn{3}{|l|}{ Years since LMP (N, \%) } \\
\hline$<5$ & 76 & 19.8 \\
\hline 5 to 10 & 104 & 27.1 \\
\hline$>10$ & 204 & 53.1 \\
\hline Body mass index, kg/m2 (Mean, SD) & 26.7 & 5.6 \\
\hline \multicolumn{3}{|l|}{ Stage $(\mathrm{N}, \%)$} \\
\hline 0 and I & 149 & 38.2 \\
\hline$\|$ & 200 & 51.3 \\
\hline III & 41 & 10.5 \\
\hline \multicolumn{3}{|l|}{ Chemotherapy (N, \%) } \\
\hline None & 143 & 36.7 \\
\hline Chemotherapy, but no Taxane & 97 & 24.9 \\
\hline Chemotherapy included Taxane & 150 & 38.5 \\
\hline Currently on Als & 355 & 91 \\
\hline \multicolumn{3}{|l|}{ Aromatase inhibitors $^{1}$} \\
\hline Letrozole (Femara) & 71 & 20.0 \\
\hline Anastrozole (Arimidex) & 241 & 67.9 \\
\hline Exemestane (Aromasin) & 43 & 12.1 \\
\hline \multicolumn{3}{|l|}{ Years since start of $\mathrm{Al}^{1}$} \\
\hline$<1$ & 114 & 31.9 \\
\hline 1 to 3 & 111 & 31.1 \\
\hline$>3$ & 132 & 37.0 \\
\hline
\end{tabular}

Abbreviations: Als, aromatase inhibitors; LMP, last menstrual period; SD, standard deviation.

${ }^{1}$ Among those who are currently on Als.

Not all cells add up due to missing variables. 
AI treatment, median time since discontinuation (IQR) was 10.2 months (31).

\section{Patient-reported Al-associated arthralgia}

Among the participants, 198 (50.8\%) reported joint symptoms attributable to AI or cited arthralgia as reason for their discontinuation of AIs, and were therefore classified as having AIAA. Risk of AIAA was non-statistically higher among those who stopped AIs than among those who were currently on AIs $(62.9 \%$ vs. $49.6 \%, P=$ $0.13)$. Shorter time since menopause $(P<0.001)$, exposure to chemotherapy including taxane $(P=0.006)$, and one to three years since the start of AI exposure $(P=$ $0.02)$ appeared to be associated with greater report of AAIA in univariate analysis (Table 2). Those with AIAA were significantly younger than those without AIAA (59 vs. $65, P<0.001$ ) but had similar body mass index (BMI) (27.3 vs. 27.6, $P=0.85$ ).

\section{CYP19A1 polymorphisms}

All genotyping failure rates were $<1.8 \%$. Genotype distributions were in Hardy-Weinberg equilibrium and were consistent with reported reference SNP frequencies. Univariate associations between CYP19A1 (aromatase) polymorphisms and study outcomes demonstrated that subjects with at least one (TTTA) $)_{7}$ repeat allele had higher risk of AIAA, while subjects with at least one $(\text { TTTA })_{8}$ repeat allele had lower risk of AIAA (Table 3).

\section{Multivariable analysis}

Multivariable models examining the association between AIAA and TTTA ${ }_{7}$ and TTTA $A_{8}$ genotypes were adjusted for time since LMP, reason for menopause, time since start of AI therapy, education level, and chemotherapy. Age was not included in the model because of co-linearity with time since LMP. Subjects carrying at least one 7-repeat allele had a non-significant 1.7-fold increase in odds of AIAA $(P=0.028)$ after correcting for multiple testing, while subjects carrying an 8-repeat allele had a significantly decreased odds of AIAA (OR 0.41 (0.21, 0.79 ), $P=0.008$ ) (Table 4). In these models, the only significant clinical predictor of AIAA was time since menopause, with those who were less than five years from their LMP at three-fold increased odds of reporting AAIA than those who were more than 10 years from their LMP.

\section{Estrogen levels}

Because AIs are known to result in profound estrogen deprivation, we sought to establish the feasibility of quantifying estrogen levels on women receiving AIs. Of 320 subjects who were currently on AIs and had samples available for estrogen analyses, estradiol was detectable in 150 subjects (46.9\%), while estrone was detectable in
Table 2 Clinical and demographic variables and risk of AAIA

\begin{tabular}{|c|c|c|c|}
\hline \multirow[t]{2}{*}{ Characteristic } & \multicolumn{2}{|c|}{$\begin{array}{l}\text { Reported AIAA } \\
(N=390)\end{array}$} & \multirow[t]{2}{*}{$P$-value ${ }^{2}$} \\
\hline & $\mathbf{N}$ & $\%$ & \\
\hline Educational Level & & & 0.11 \\
\hline High school or less & 29 & 42.0 & \\
\hline College or more & 169 & 52.7 & \\
\hline Reasons for menopause & & & 0.13 \\
\hline Natural & 98 & 47.6 & \\
\hline Induced & 91 & 55.5 & \\
\hline Years since LMP & & & $<.001$ \\
\hline$<5$ & 50 & 65.8 & \\
\hline 5 to 10 & 63 & 60.6 & \\
\hline$>10$ & 83 & 40.7 & \\
\hline Body mass index & & & 0.62 \\
\hline$<25$ & 97 & 50.5 & \\
\hline 25 to 30 & 68 & 45.3 & \\
\hline$>30$ & 68 & 49.3 & \\
\hline Stage & & & 0.991 \\
\hline 0 and I & 75 & 50.4 & \\
\hline$\|$ & 102 & 51.0 & \\
\hline III & 21 & 51.2 & \\
\hline Chemotherapy & & & 0.006 \\
\hline None & 59 & 41.3 & \\
\hline Chemotherapy, but no Taxane & 49 & 50.2 & \\
\hline Chemotherapy included Taxane & 90 & 60.0 & \\
\hline Aromatase inhibitors & & & 0.62 \\
\hline Letrozole (Femara) & 33 & 46.5 & \\
\hline Anastrozole (Arimidex) & 119 & 49.4 & \\
\hline Exemestane (Aromasin) & 24 & 55.8 & \\
\hline Years since start of $\mathrm{Al}^{1}$ & & & 0.02 \\
\hline$<1$ & 56 & 49.1 & \\
\hline 1 to 3 & 67 & 59.6 & \\
\hline$>3$ & 55 & 41.7 & \\
\hline \multicolumn{4}{|l|}{ Estrogen levels } \\
\hline Detectable estradiol & 74 & 47.4 & 0.84 \\
\hline Detectable estrone & 134 & 85.9 & 0.73 \\
\hline
\end{tabular}

Abbreviations: AIAA, Aromatase Inhibitor associated Arthralgia; LMP, last menstrual period.

${ }^{1}$ Among those who are currently on Als.

${ }^{2}$ Chi-square.

277 subjects (86.6\%). The median (range) estradiol and estrone levels were $<1.5 \mathrm{pg} / \mathrm{mL}(<1.5,40.3)$ and $3.3 \mathrm{pg} /$ $\mathrm{mL}(<1.7,60.3)$, respectively (Figure 1$)$. Estradiol $(P=$ $0.88)$ and estrone $(P=0.78)$ levels were no different by AAIA status.

For subjects who were currently taking AIs, estrone levels were associated with multiple genotypes. At the 3'UTR locus, carriers of the variant $\mathrm{T}$ allele had higher estrone levels (median (range)) compared to the homozygous wildtype $(3.3 \mathrm{pg} / \mathrm{mL}(<1.7,69.1)$ versus $3.1 \mathrm{pg} / \mathrm{mL}$ $(<1.7,32.4), P=0.03)$. Variant genotypes at the IVS2 
Table 3 Genotypes and risk of AIAA ${ }^{1}$

\begin{tabular}{|c|c|c|c|c|}
\hline \multirow[t]{2}{*}{ Polymorphism } & \multicolumn{2}{|c|}{ Genotype frequency } & \multicolumn{2}{|c|}{ AIAA } \\
\hline & Genotype & $\%(\mathrm{~N})$ & $\%(\mathrm{~N})$ & $P$-value ${ }^{2}$ \\
\hline & $\mathrm{C} / \mathrm{C}$ & $28.1(107)$ & $50(54)$ & \\
\hline \multirow[t]{2}{*}{ 3' UTR C/T (rs10046) } & $\mathrm{C} / \mathrm{T}$ & $47.8(182)$ & $54(98)$ & 0.20 \\
\hline & $\mathrm{T} / \mathrm{T}$ & $24.1(92)$ & $42(39)$ & \\
\hline \multirow{3}{*}{ IVS1 A/G (rs749292) } & $\mathrm{G} / \mathrm{G}$ & $30.8(118)$ & $54(63)$ & \\
\hline & $\mathrm{G} / \mathrm{A}$ & $52.2(200)$ & $48(96)$ & 0.57 \\
\hline & A/A & $17.0(65)$ & $54(35)$ & \\
\hline \multirow{3}{*}{ IVS2 G/T (rs727479) } & $\mathrm{G} / \mathrm{G}$ & $13.1(50)$ & $50(25)$ & \\
\hline & $\mathrm{G} / \mathrm{T}$ & $42.7(163)$ & $52(84)$ & 0.94 \\
\hline & $\mathrm{T} / \mathrm{T}$ & $44.2(169)$ & $50(84)$ & \\
\hline \multirow{3}{*}{ IVS4 -/TCT (rs11575899) } & $\mathrm{TCT} / \mathrm{TCT}$ & $44.8(172)$ & $49(84)$ & \\
\hline & TCT/- & 41.4 (159) & $51(81)$ & 0.86 \\
\hline & $-/-$ & $13.8(53)$ & $53(28)$ & \\
\hline \multirow{10}{*}{ (TTTA)n (rs60271534) } & No 7 repeat & $28.8(109)$ & $42(46)$ & 0.03 \\
\hline & Any 7 repeat & $71.2(270)$ & $55(148)$ & \\
\hline & No 8 repeat & $87.1(330)$ & $53(176)$ & 0.03 \\
\hline & Any 8 repeat & $12.9(49)$ & $37(18)$ & \\
\hline & No 10 repeat & 88.7 (336) & $51(173)$ & 0.75 \\
\hline & Any 10 repeat & $11.3(43)$ & $49(21)$ & \\
\hline & No 11 repeat & $62.2(234)$ & $52(121)$ & 0.92 \\
\hline & Any 11 repeat & $37.8(142)$ & $51(72)$ & \\
\hline & No 12 repeat & $88.7(336)$ & $51(170)$ & 0.63 \\
\hline & Any 12 repeat & $11.3(43)$ & $56(24)$ & \\
\hline
\end{tabular}

Abbreviations: AIAA, Aromatase Inhibitor Associated Arthralgia.

${ }^{1}$ Among Caucasian subjects.

${ }^{2}$ Chi-square. polymorphism also had significantly higher estrone levels than the homozygous wildtype genotype $(3.3 \mathrm{pg} / \mathrm{mL}$ $(<1.7,69.1)$ versus $2.0 \mathrm{pg} / \mathrm{mL}(<1.7,26.7), P=0.01)$. For the IVS4 polymorphism, the homozygous variant genotype (TCT -/-) was associated with higher estrone levels compared to carriers of the TCT allele $(6.3(<1.7,18.3)$ versus $2.9(<1.7,32.4), P=0.02)$. Estradiol levels were not associated with genotypes in this dataset. As expected, estrogen levels were significantly lower in women currently on AIs $(P<0.001$ for both estradiol and estrone) than those who discontinued AIs. Furthermore, higher estrogen levels were associated with shorter time since menopause $(P<0.002$ for estrone; $P=0.01$ for estradiol).

\section{Discussion}

The introduction of AIs as treatment for hormone receptor-positive breast cancer has improved disease free survival for many women; however, arthralgia related to AIs has caused significant symptom distress and may contribute to premature discontinuation among users [16]. We have found that germline polymorphic repeats in CYP19A1, the gene encoding aromatase enzyme, are associated with the occurrence of AIAA. Additionally, the study confirmed our prior findings that shorter time since menopause was a significant clinical predictor of report of AAIA [3]. These data provide evidence that the host estrogen environment plays an important role in the occurrence of AIAA and helps

Table 4 Multivariable logistic regression analyses: CYP19A variant and AIAA

\begin{tabular}{|c|c|c|c|c|}
\hline Risk factors & AOR (95\% C.I.) & $P$-value & AOR (95\% C.I.) & $P$-value \\
\hline Genotype & CYP19A 7r & & CYP19A 8r & \\
\hline Non-carrier (Reference) & 1 & - & 1 & - \\
\hline Carrier & 1.70 (1.06 to 2.73$)$ & 0.028 & 0.41 (0.21 to 0.79$)$ & 0.008 \\
\hline \multicolumn{5}{|l|}{ Time since LMP } \\
\hline$>10$ years (Reference) & 1 & - & 1 & - \\
\hline 5 to 10 years & 2.15 (1.27 to 3.67$)$ & 0.005 & 2.14 (1.26 to 3.66$)$ & 0.005 \\
\hline$<5$ years & 3.28 (1.71 to 6.29$)$ & $<0.001$ & 3.31 (1.72 to 6.39$)$ & $<0.001$ \\
\hline \multicolumn{5}{|l|}{ Type of menopause } \\
\hline Natural (Reference) & 1 & - & 1 & - \\
\hline Induced & 0.82 (0.55 to 1.21$)$ & 0.32 & 0.81 (0.55 to 1.20$)$ & 0.30 \\
\hline \multicolumn{5}{|l|}{ Years since start of Al } \\
\hline$<1$ year (Reference) & 1 & - & 1 & - \\
\hline 1 to 3 years & 1.45 (0.82 to 2.58$)$ & 0.20 & 1.48 (0.83 to 2.62$)$ & 0.18 \\
\hline$>3$ years & 0.78 (0.45 to 1.33 ) & 0.36 & 0.77 (0.45 to 1.33$)$ & 0.35 \\
\hline \multicolumn{5}{|l|}{ Education } \\
\hline High school & 1 & - & 1 & - \\
\hline College and graduate school & 1.02 (0.76 to 1.38$)$ & 0.87 & 1.05 (0.78 to 1.43$)$ & 0.93 \\
\hline \multicolumn{5}{|l|}{ Chemotherapy } \\
\hline None (Reference) & 1 & - & 1 & - \\
\hline Chemotherapy but no taxane & 0.97 (0.54 to 1.74$)$ & 0.92 & $1.02(0.57$ to 1.83$)$ & 0.85 \\
\hline Chemotherapy included taxane & 1.52 (0.89 to 2.61$)$ & 0.12 & 1.61 (0.93 to 2.78$)$ & 0.09 \\
\hline
\end{tabular}

Abbreviations: AOR, adjusted odds ratio; $95 \% \mathrm{Cl}, 95 \%$ confidence interval; LMP, last menstrual period. 


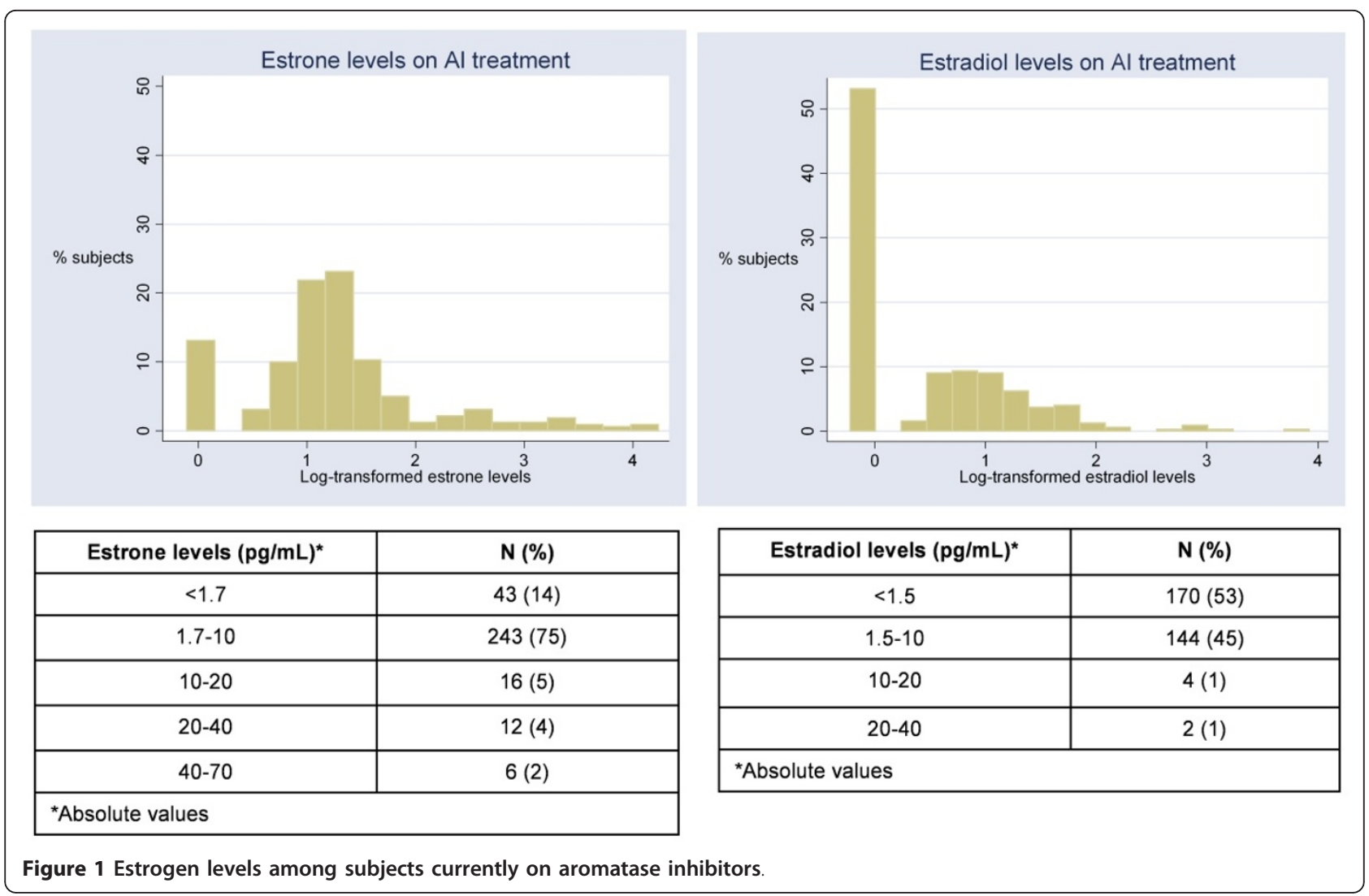

explain part of the inter-individual variability in symptom experience among patients taking these agents.

The high rate of AIAA in this study confirms previous reports that AIAA affects almost half of the ambulatory patients who receive AIs $[3,4]$. These rates are much higher than reported in clinical trial settings $(18.6 \%$ to $35.6 \%$ ) [17-20] and may be a result of the differences in patient-reported outcomes versus clinician ascertained toxicity [21]. Emerging research suggests that patient reported toxicity more comprehensively capture the subjective side effects of therapies (that is, pain) on daily experience and have higher concordance with healthrelated quality of life than clinician ascertained toxicity; therefore, it is more appropriate for the investigation of AIAA [22,23]. Further, only a very small proportion of all cancer patients participate in clinical trials [24]. Thus, it is possible that selection bias in clinical trial participants may also lead to decreased incidence of reported AIAA than the rate in ambulatory settings.

We have identified promising associations between genetic variation in aromatase and AIAA. Carriers of at least one 7-repeat allele in the tetranucleotide repeat polymorphism had non-significant higher risk of AAIA, while carriers of at least one 8-repeat allele had significant lower risk. TTTA ${ }_{7}$ has been associated with lower estrogen levels in postmenopausal women and TTTA ${ }_{8}$ has been associated with higher estrogen levels [14]. These relationships support one possible hypothesis: women with aromatase enzyme polymorphisms associated with lower pre-AI estrogen levels undergo further estrogen depletion with AI exposure, thereby rendering them at higher risk of developing AAIA. Other functional polymorphisms and haplotypes in aromatase that are related to estrogen levels have been described in resequencing projects $[14,25]$, but we did not find a significant association between several of these candidate polymorphisms and AIAA. An alternative hypothesis may be that genetic polymorphisms in aromatase gene may impact the efficacy of aromatase inhibitors and produce varying degrees of estrogen deprivation. Further prospective study combining genotyping, high sensitivity estrogen measurements and AIAA may help test these hypotheses.

Since AIs are known to cause profound estrogen deprivation, measuring estrogen levels in AI users is essential to laying the groundwork for further understanding the relationship between these levels and AIAA. Our assay was highly reliable and extraction methods minimized measurement of other estrogen metabolites and drug metabolites of exemestane. However, we did not find a difference in post-AI estrogen levels by AIAA status. One explanation may be the 
already low overall levels of these circulating sex hormones observed in the study. Although a highly sensitive RIA method was used, a significant proportion of subjects had estradiol and/or estrone levels below the level of detection, limiting our discrimination. Presently, the assay sensitivity for mass spectrometry (MS) for estradiol is similar to our method ( 1 to $2 \mathrm{pg} / \mathrm{mL}$ ). However, as MS technology advances, it will be possible to measure extremely low estrogen levels, in the femotogram range, and improve discrimination [26]. Another explanation is that although we restricted our analysis to those who self-report current use of AIs, it is possible that imperfect adherence to AIs may introduce variability in estrogen levels and thus confound the analysis between estrogen levels and AIAA towards null. Finally, a likely explanation may be that since arthralgia occurs with the exposure of AIs, it is possible that pre-AI estrogen levels or a change in estrogen levels resulting from AI exposure are more critical to the development of AIAA. Our findings of an inverse relationship between time since menopause and estrogen levels and AIAA risk support this hypothesis.

Although estradiol and estrone levels were not associated with AIAA, estrone levels were significantly different among multiple genotypes in the expected direction. Homozygotes for the $t$ allele at 3'UTR, (TCT) + allele at IVS4 and t allele at IVS2 have been observed to have higher postmenopausal levels of estradiol and estrone [9]. Estrogen levels were no different among other genotypes, including $\mathrm{TTTA}_{n}$, a finding that may also be due to the low circulating hormone levels on AIs. In these results, we have shown that the relationship between genotype and estrogen levels remained for some variants even in the setting of AI exposure, and that estrone rather than estradiol levels were measurably different. This suggests the utility of estrone as a potential hormonal biomarker in AI users.

Finally, assessing estradiol and estrone levels in a large cohort of women exposed to AIs has only been done in one recent study $[27,28]$. Using purification steps to optimize specificity and highly sensitive estradiol and estrone radioimmunoassays, we demonstrated that a large proportion of women had both measurable estrone and estradiol levels. Furthermore, those women who discontinued AI therapy had higher estrogen levels than those who continued. Given the increased concerns about non-adherence in the setting of adjuvant hormonal treatment $[29,30]$, the appropriate measurement of these hormones may help determine how post-AI hormones relate to AI-adherence, breast cancer recurrence, and overall survival in longitudinal studies.

It is important to acknowledge the limitations of the study. Our outcomes were based on patient-report and may be subject to recall bias; however, patient-reported outcomes are considered the gold standard in symptom and pain research. Further the prevalence and risk of AIAA in this study were similar to prior samples by our group and others $[3,4]$, lending credence to this outcome classification. As with any genetic epidemiology study, our results are subject to false-positive discovery; however, our Bonferroni correction strengthens the possibility that this finding is robust. These results warrant further confirmatory analysis in larger and independent cohorts. Third, our cross-sectional study design helps identify a gene-symptom association that will require the prospective investigation in the setting of pre and post AI-exposure and incorporate validated patientreported outcomes of joint pain as well as high sensitivity estrogen analyses to further determine the role of estrogen deprivation on AIAA. Finally, although our overall sample had significant proportions of nonCaucasian subjects, the samples were too small for meaningful genetic analysis; collaborative studies need to be established to study how genetic polymorphisms affect AIAA in minority populations.

\section{Conclusions}

This is the largest study to date of patient-reported outcomes among ambulatory patients taking AIs for adjuvant breast cancer treatment and the first one to report genetic determinants of AIAA. These data provide preliminary evidence that genes in estrogen synthesis may modify the risk of AIAA. We also established the feasibility of measuring the estrogen levels of ambulatory AIusers which allows for future prospective investigation of the complex relationship among genetic variations, hormonal changes, and AI related arthralgia and breast cancer outcomes. It is conceivable that one day, the combination of genetic and hormonal information may help clinicians and patients decide how best to use AIs to maximize benefits, minimize side effects, and optimize both quality of life and survival in women with breast cancer.

\section{Abbreviations}

Al: aromatase inhibitor; AIAA: aromatase inhibitor associated arthralgia; AOR: adjusted odds ratio; BMl: body mass index; 95\% Cl: 95\% confidence interval; LMP: last menstrual period; RIA: radioimmunoassay.

\section{Acknowledgements}

We would like to thank all the breast cancer survivors, physicians, nurse practitioners, and staff for their support. We would like to thank Krupali Desai, Luke Velder, and Donna Chen for their dedication to the data collection and management process.

Funding Support: Penn Clinical Pharmacogenomic Epidemiology Pilot Grant (5P20RR020741), NIH AT004695, ACS CCCDA-08-107-02 (JJM), NIH 1 K23 AT004112-03 (JJM), ACS MRSG-08-110-01-CCE (HIS), NIH HD-058799-01 (HIS).

\section{Author details}

${ }^{1}$ Department of Family Medicine and Community Health, University of Pennsylvania School of Medicine, 3400 Spruce Street/2 Gates, Philadelphia, PA 
19104, USA. ${ }^{2}$ Abramson Cancer Center, University of Pennsylvania School of Medicine, 3400 Spruce Street/2 Gates, Philadelphia, PA 19104, USA. ${ }^{3}$ Department of Reproductive Medicine, University of California School of Medicine, San Diego, 3855 Health Sciences Drive, Dept. 0901, La Jolla, CA 92093-0901, USA. ${ }^{4}$ Center for Clinical Epidemiology and Biostatistics, University of Pennsylvania School of Medicine, 423 Guardian Drive, Philadelphia, PA 19104, USA. ${ }^{5}$ Department of Hematology/Oncology, Children's Hospital of Philadelphia, 4018 CTRB, 3501 Civic Center Boulevard, Philadelphia PA 19104, USA. ${ }^{6}$ Department of Medicine, Division of Hematology/Oncology, University of Pennsylvania School of Medicine, Perelman Center, 3rd Floor, 3400 Civic Center Blvd., Philadelphia, PA 19104, USA.

\section{Authors' contributions}

$J J M, H I S$ and $A D$ participated in the design of the study and management of study-related data collection. RF performed statistical analyses. MH and RA performed DNA sequencing. TTR assisted data interpretation, and FZS performed estrogen analyses. All authors have read and approved the final manuscript.

\section{Competing interests}

The authors declare that they have no competing interests.

Received: 18 October 2010 Revised: 23 December 2010

Accepted: 20 January 2011 Published: 20 January 2011

\section{References}

1. Chlebowski RT: Aromatase inhibitor-associated arthralgias. J Clin Oncol 2009, 27:4932-4934.

2. Coleman RE, Bolten WW, Lansdown M, Dale S, Jackisch C, Merkel D, Maass N, Hadji P: Aromatase inhibitor-induced arthralgia: Clinical experience and treatment recommendations. Cancer Treat Rev 2008, 34:275-282.

3. Mao JJ, Stricker C, Bruner D, Xie S, Bowman MA, Farrar JT, Greene BT, DeMichele A: Patterns and risk factors associated with aromatase inhibitor-related arthralgia among breast cancer survivors. Cancer 2009, 115:3631-3639

4. Crew KD, Greenlee H, Capodice J, Raptis G, Brafman L, Fuentes D, Sierra A Hershman DL: Prevalence of joint symptoms in postmenopausal women taking aromatase inhibitors for early-stage breast cancer. J Clin Oncol 2007, 25:3877-3883.

5. Morales L, Pans S, Verschueren K, Van Calster B, Paridaens R, Westhovens R, Timmerman D, De Smet L, Vergote I, Christiaens MR, Neven P: Prospective study to assess short-term intra-articular and tenosynovial changes in the aromatase inhibitor-associated arthralgia syndrome. J Clin Oncol 2008, 26:3147-3152.

6. Donnellan PP, Douglas SL, Cameron DA, Leonard RC: Aromatase inhibitors and arthralgia. J Clin Oncol 2001, 19:2767.

7. Felson DT, Cummings SR: Aromatase inhibitors and the syndrome of arthralgias with estrogen deprivation. Arthritis Rheum 2005, 52:2594-2598.

8. Dugan SA, Powell LH, Kravitz HM, Everson Rose SA, Karavolos K, Luborsky J: Musculoskeletal pain and menopausal status. Clin J Pain 2006, 22:325-331.

9. Dunning AM, Dowsett M, Healey CS, Tee L, Luben RN, Folkerd E, Novik KL, Kelemen L, Ogata S, Pharoah PD, Easton DF, Day NE, Ponder BA: Polymorphisms associated with circulating sex hormone levels in postmenopausal women. J Natl Cancer Inst 2004, 96:936-945.

10. Haiman CA, Hankinson SE, Spiegelman D, De Vivo I, Colditz GA, Willett WC, Speizer FE, Hunter DJ: A tetranucleotide repeat polymorphism in CYP19 and breast cancer risk. Int J Cancer 2000, 87:204-210.

11. Tworoger SS, Chubak J, Aiello EJ, Ulrich CM, Atkinson C, Potter JD, Yasui Y, Stapleton PL, Lampe JW, Farin FM, Stanczyk FZ, McTiernan A: Association of CYP17, CYP19, CYP1B1, and COMT polymorphisms with serum and urinary sex hormone concentrations in postmenopausal women. Cancer Epidemiol Biomarkers Prev 2004, 13:94-101.

12. Woods NF, Mitchell ES, Tao Y, Viernes HM, Stapleton PL, Farin FM: Polymorphisms in the estrogen synthesis and metabolism pathways and symptoms during the menopausal transition: observations from the Seattle Midlife Women's Health Study. Menopause 2006, 13:902-910.

13. Fontaine C, Meulemans A, Huizing M, Collen C, Kaufman L, De Mey J, Bourgain C, Verfaillie G, Lamote J, Sacre R, Schallier D, Neyns B,
Vermorken J, De Greve J: Tolerance of adjuvant letrozole outside of clinical trials. Breast 2008, 17:376-381.

14. Haiman CA, Dossus L, Setiawan WW, Stram DO, Dunning AM, Thomas G, Thun MJ, Albanes D, Altshuler D, Ardanaz E, Boeing H, Buring J, Burtt N, Calle EE, Chanock S, Clavel-Chapelon F, Colditz GA, Cox DG, Feigelson HS, Hankinson SE, Hayes RB, Henderson BE, Hirschhorn JN, Hoover R, Hunter DJ, Kaaks R, Kolonel LN, Le Marchand L, Lenner P, Lund E, et al: Genetic variation at the CYP19A1 locus predicts circulating estrogen levels but not breast cancer risk in postmenopausal women. Cancer Res 2007, 67:1893-1897.

15. Kelberman D, Fife M, Rockman MV, Brull DJ, Woo P, Humphries SE: Analysis of common IL-6 promoter SNP variants and the AnTn tract in humans and primates and effects on plasma IL-6 levels following coronary artery bypass graft surgery. Biochim Biophys Acta 2004, 1688:160-167.

16. Burstein HJ, Winer EP: Aromatase inhibitors and arthralgias: a new frontier in symptom management for breast cancer survivors. J Clin Oncol 2007, 25:3797-3799.

17. Coates AS, Keshaviah A, Thurlimann B, Mouridsen H, Mauriac L, Forbes JF, Paridaens R, Castiglione-Gertsch M, Gelber RD, Colleoni M, Lang I, Del Mastro L, Smith I, Chirgwin J, Nogaret JM, Pienkowski T, Wardley A, Jakobsen EH, Price KN, Goldhirsch A: Five years of letrozole compared with tamoxifen as initial adjuvant therapy for postmenopausal women with endocrine-responsive early breast cancer: update of study BIG 1-98. J Clin Oncol 2007, 25:486-492.

18. Coombes RC, Kilburn LS, Snowdon CF, Paridaens R, Coleman RE, Jones SE, Jassem J, Van de Velde CJ, Delozier T, Alvarez I, Del Mastro L, Ortmann O, Diedrich K, Coates AS, Bajetta E, Holmberg SB, Dodwell D, Mickiewicz E, Andersen J, Lonning PE, Cocconi G, Forbes J, Castiglione M, Stuart N, Stewart A, Fallowfield LJ, Bertelli G, Hall E, Bogle RG, Carpentieri M, et al: Survival and safety of exemestane versus tamoxifen after 2-3 years' tamoxifen treatment (Intergroup Exemestane Study): a randomised controlled trial. Lancet 2007, 369:559-570.

19. Goss PE, Ingle JN, Martino S, Robert NJ, Muss HB, Piccart MJ, Castiglione M, Tu D, Shepherd LE, Pritchard KI, Livingston RB, Davidson NE, Norton L, Perez EA, Abrams JS, Cameron DA, Palmer MJ, Pater JL: Randomized trial of letrozole following tamoxifen as extended adjuvant therapy in receptor-positive breast cancer: updated findings from NCIC CTG MA.17. J Natl Cancer Inst 2005, 97:1262-1271.

20. Howell A, Cuzick J, Baum M, Buzdar A, Dowsett M, Forbes JF, HoctinBoes G, Houghton J, Locker GY, Tobias JS: Results of the ATAC (Arimidex, Tamoxifen, Alone or in Combination) trial after completion of 5 years' adjuvant treatment for breast cancer. Lancet 2005, 365:60-62.

21. Basch E, lasonos A, McDonough T, Barz A, Culkin A, Kris MG, Scher HI, Schrag D: Patient versus clinician symptom reporting using the National Cancer Institute Common Terminology Criteria for Adverse Events: results of a questionnaire-based study. Lancet Oncol 2006, 7:903-909.

22. Basch E, Jia X, Heller G, Barz A, Sit L, Fruscione M, Appawu M, lasonos A, Atkinson T, Goldfarb S, Culkin A, Kris MG, Schrag D: Adverse symptom event reporting by patients vs clinicians: relationships with clinical outcomes. J Natl Cancer Inst 2009, 101:1624-1632.

23. Neben-Wittich MA, Atherton PJ, Schwartz DJ, Sloan JA, Griffin PC, Deming RL, Anders JC, Loprinzi CL, Burger KN, Martenson JA, Miller RC: Comparison of provider-assessed and patient-reported outcome measures of acute skin toxicity during a phase iii trial of mometasone cream versus placebo during breast radiotherapy: The North Central Cancer Treatment Group (N06C4). Int J Radiat Oncol Biol Phys 2010.

24. Murthy VH, Krumholz HM, Gross CP: Participation in cancer clinical trials: race-, sex-, and age-based disparities. JAMA 2004, 291:2720-2726.

25. Ma CX, Adjei AA, Salavaggione OE, Coronel J, Pelleymounter L, Wang L, Eckloff BW, Schaid D, Wieben ED, Adjei AA, Weinshilboum RM: Human aromatase: gene resequencing and functional genomics. Cancer Res 2005, 65:11071-11082.

26. Stanczyk FZ, Clarke NJ: Advantages and challenges of mass spectrometry assays for steroid hormones. J Steroid Biochem Mol Biol 2010, 121:491-495.

27. Ingle JN, Buzdar AU, Schaid DJ, Goetz MP, Batzler A, Robson ME, Northfelt DW, Olson JE, Perez EA, Desta Z, Weintraub RA, Williard CV, Flockhart DA, Weinshilboum RM: Variation in anastrozole metabolism and pharmacodynamics in women with early breast cancer. Cancer Res 2010, 70:3278-3286.

28. Dixon JM, Renshaw L, Young O, Murray J, Macaskill EJ, McHugh M, Folkerd E, Cameron DA, A'Hern RP, Dowsett M: Letrozole suppresses 
plasma estradiol and estrone sulphate more completely than anastrozole in postmenopausal women with breast cancer. J Clin Oncol 2008, 26:1671-1676.

29. Partridge AH, Wang PS, Winer EP, Avorn J: Nonadherence to adjuvant tamoxifen therapy in women with primary breast cancer. Journal of Clinical Oncology 2003, 21:602-606.

30. Hershman DL, Kushi LH, Shao T, Buono D, Kershenbaum A, Tsai WY

Fehrenbacher L, Gomez SL, Miles S, Neugut Al: Early discontinuation and nonadherence to adjuvant hormonal therapy in a cohort of 8,769 earlystage breast cancer patients. J Clin Oncol 2010, 28:4120-4128.

doi:10.1186/bcr2813

Cite this article as: Mao et al: Association of functional polymorphisms in CYP19A1 with aromatase inhibitor associated arthralgia in breast cancer survivors. Breast Cancer Research 2011 13:R8.

Submit your next manuscript to BioMed Central and take full advantage of:

- Convenient online submission

- Thorough peer review

- No space constraints or color figure charges

- Immediate publication on acceptance

- Inclusion in PubMed, CAS, Scopus and Google Scholar

- Research which is freely available for redistribution

Submit your manuscript at www.biomedcentral.com/submit 